\title{
Design of a National Radioactivity Monitoring Programme (NRMP) to monitor surface water resources in South Africa
}

\author{
I. Sekoko ${ }^{1}$, A. Kühn ${ }^{1}$, P. Kempster ${ }^{1}$, B. Madikizela ${ }^{1}$, \\ H. van Niekerk ${ }^{1}$, M. van Veelen ${ }^{2} \&$ J. Slabbert ${ }^{3}$ \\ ${ }^{1}$ Department of Water Affairs and Forestry: Resource Quality Services, \\ South Africa \\ ${ }^{2} B K S$ (PTY) LTD, South Africa \\ ${ }^{3}$ PSI Risk Consulting, South Africa
}

\begin{abstract}
The Department of Water Affairs and Forestry (DWAF) has carried out a number of case studies on the radiological quality for the water resources near gold mining activities in South Africa. Elevated levels of radioactivity were found in some areas. It thus became important to establish a national monitoring programme that will report on the radiological quality of South Africa's water resources in order to comply with the water resource quality monitoring requirements of the National Water Act (Act 36 of 1998). The purpose of the National Radioactivity Monitoring Programme (NRMP) is to establish the status of, and trends in, radioactivity levels in South African water resources and to report on their radiological quality on a regular basis.

This paper discusses issues and decisions taken with regard to the design of the NRMP. A screening method, using alpha/beta activity is proposed to estimate total radioactivity in surface water resources. Where elevated levels of radioactivity have been identified, an element specific analysis will follow. A biweekly sampling frequency has been recommended. Sampling site selection is catchment based and includes sites in high-risk areas. Where possible, use will be made of existing water quality and flow monitoring sites.

Keywords: National Radioactivity Monitoring Programme, status, trends, radiological quality, water resources and surface water.
\end{abstract}




\section{Introduction}

Following a number of case studies carried out by the Department of Water Affairs and Forestry (DWAF) on the radiological quality of water resources near gold mining activities in South Africa, it became important to establish a national monitoring programme to allay public fears. This programme will report on the status of, and trends in, the radiological quality of South Africa's water resources as part of the water resource quality monitoring requirements of the National Water Act (Act No. 36 of 1998).

The aim of the National Water Act (NWA) is to ensure that the nation's water resources are protected, used, developed, conserved, managed and controlled in ways that take into account amongst other things:

- Meeting of basic human needs of present and future generations

- Ensuring the protection of aquatic and associated ecosystems and their biological diversity

- $\quad$ Reducing and preventing pollution and degradation of water resources.

The Water Act mandates the Minister of DWAF to establish national monitoring systems that monitor, record, assess and disseminate information on water resources. The quality of the water resource and its effect on the environment, agriculture, industry, recreation and human health need to be known and well understood in order to meet the main requirements of the Act, viz., to protect and sustain water resources of South Africa for present and future generations.

Due to the fact that only limited information on the radiological quality of water resources is available in South Africa, a National Radioactivity Monitoring Programme (NRMP) was initiated. The development of the programme is divided into four phases. Phase 1 an "Information needs assessment" [3] has been completed. The development of the programme is currently in Phase 2 i.e. "The design and the development of an implementation plan for the NRMP". Once the second phase has been completed, the programme will proceed to the third phase, which is "The testing of the implementation plan", and phase 4 that is "Full scale implementation of the programme".

\subsection{Aim of the NRMP}

The aim of the NRMP is to provide information on the status of, and trends in the radiological quality of South Africa's water resources.

\subsection{Purpose of the paper}

This paper presents an overview of the second phase (Phase 2) of the National Radioactivity Monitoring Programme (NRMP) with the emphasis on surface water. 


\section{Scope of the NRMP}

South Africa is divided into 19 Water Management Areas (WMA) each comprising a number of catchments. The NRMP will eventually cover all 19 WMA's. Base line radioactivity data will be collected and long term monitoring will be carried out to enable the detection of trends. The radiological quality of water resources will be assessed in terms of fitness for use based on the radiation dose a person would receive if water from a particular resource is consumed on a life long basis. The NRMP will provide a national picture on the status of radioactivity in South Africa's water resources and the extent of possible problems. This information will enable water resource managers to take strategic decisions regarding national and regional resource allocation to address the radioactivity problems in areas of concern. In terms of the scope of the NRMP, only water resources that significantly contribute to human exposure through direct ingestion will be included. The results will present an overview of the radiological quality of the country's water resources. Major rivers and dams that are geographically representative of South Africa's surface water resources and also water resources that are already adequately monitored in terms of other regulations (e.g. National Nuclear Regulatory Act. No. 47 of 1999) will be included in the NRMP.

It is important to optimise national resource quality monitoring programmes in terms of resources such as finances, manpower, field equipment and processing facilities for monitoring data. It is therefore imperative from a cost effectiveness aspect that the NRMP is not developed in isolation from the other national monitoring programmes. Co-operation with other overlapping monitoring programmes will be established to minimise costs and also to ensure sharing of data. The programme will also take into consideration international agreements especially with neighbouring countries with which rivers are shared.

\section{The design methodology}

The monitoring and assessment of water quality is based upon the physical, chemical, radiological and biological properties of water [5]. The NRMP consists of the same basic functional components as the other national monitoring programmes namely: data acquisition (including the selection of sampling sites, variables of concern, sampling frequency and analytical methods), data management and storage and information generation and dissemination. Quality control and assurance is regarded as an important cross cutting element.

\subsection{Data acquisition}

\subsubsection{Sample site selection}

Selection of sampling sites is based on the basic objectives of the programme. When selecting the sampling sites, the importance of obtaining information in the most cost-effective way was paramount. However, the system is primarily 
designed to provide water quality managers with strategic information on the status of the radiological quality of water resources in South Africa. Sampling sites were chosen such that they are geographically representative of surface water resources in SA. Factors such as geology, water use, land-use, and flow regimes of the rivers were also taken into account. The following process was used to select sampling sites:

3.1.1.1 Sites in secondary catchments. South Africa is divided into 22 primary drainage regions and these primary river catchments are subdivided into contributing secondary catchments, secondary catchments are in turn subdivided into tertiary catchments that are finally subdivided into quaternary catchments. On a macro scale one sampling site per secondary catchment (Figure 1) was selected for the NRMP. Each of these sites is representative of the outflow of a specific catchment. It was ensured that the selected sampling sites correspond to the sampling sites used for the Global Environmental Monitoring System (GEMS). Sampling sites were selected by comparing the Department of Water Affairs and Forestry's monitoring network with the data extracted from the South African Minerals Database (Figure 2).

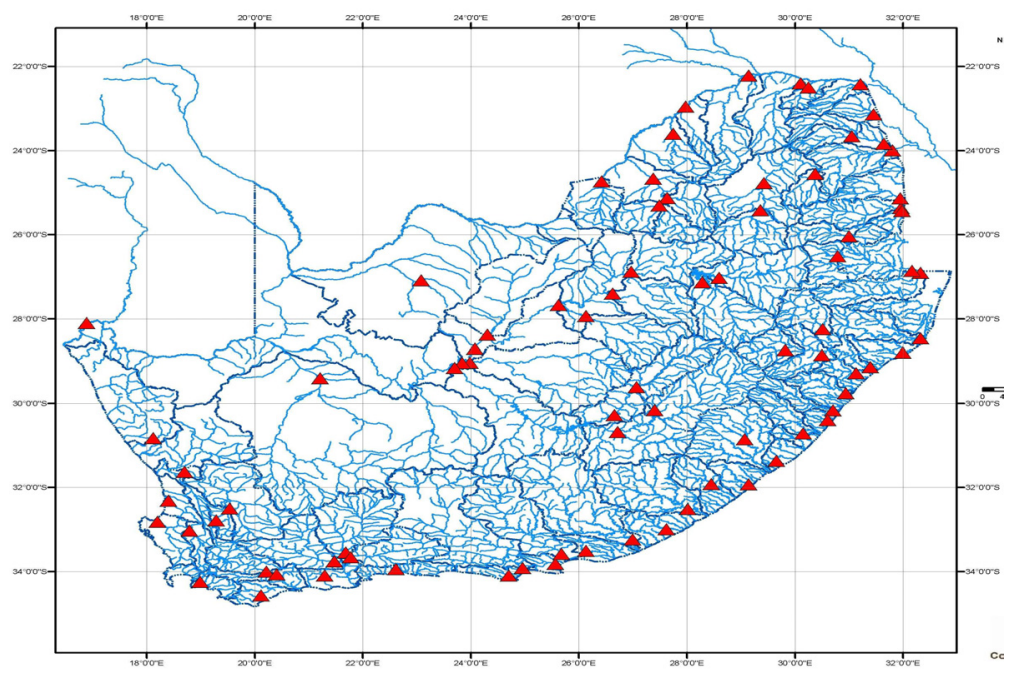

Figure 1: Selected sampling sites in Secondary catchments with sites for the Global Environmental Monitoring System (GEMS) in South Africa incorporated.

3.1.1.2 Sites in tertiary catchments. In order to be able to identify areas of concern, monitoring will be extended to tertiary catchment level where high concentrations of radionuclides are known to occur in specific geological areas, where radioactive ores are mined and processed or where certain other land-use activities could contribute to elevated levels of radioactivity in water resources. 
All known areas where radioactive minerals (uranium- or thorium-bearing ores) occur as well as sites close to nuclear industries have been selected. The major concentrations of radioactive mineral deposits are in the Witwatersrand Gold Field area with its associated uranium concentrations and in the Karoo deposits in the Northern Cape Province. Other significant deposits include carbonatite pipes such as at Phalaborwa and Salpeterkop, granite hosted uranium occurrences such as those found in the Cape Granites and in the Margate area and deposits associated with high-grade metamorphic rocks, e.g. Namaqualand and the Limpopo Mobile Belt. Where a significant number, or known major factors, occur, additional sampling sites within tertiary catchments have been selected.

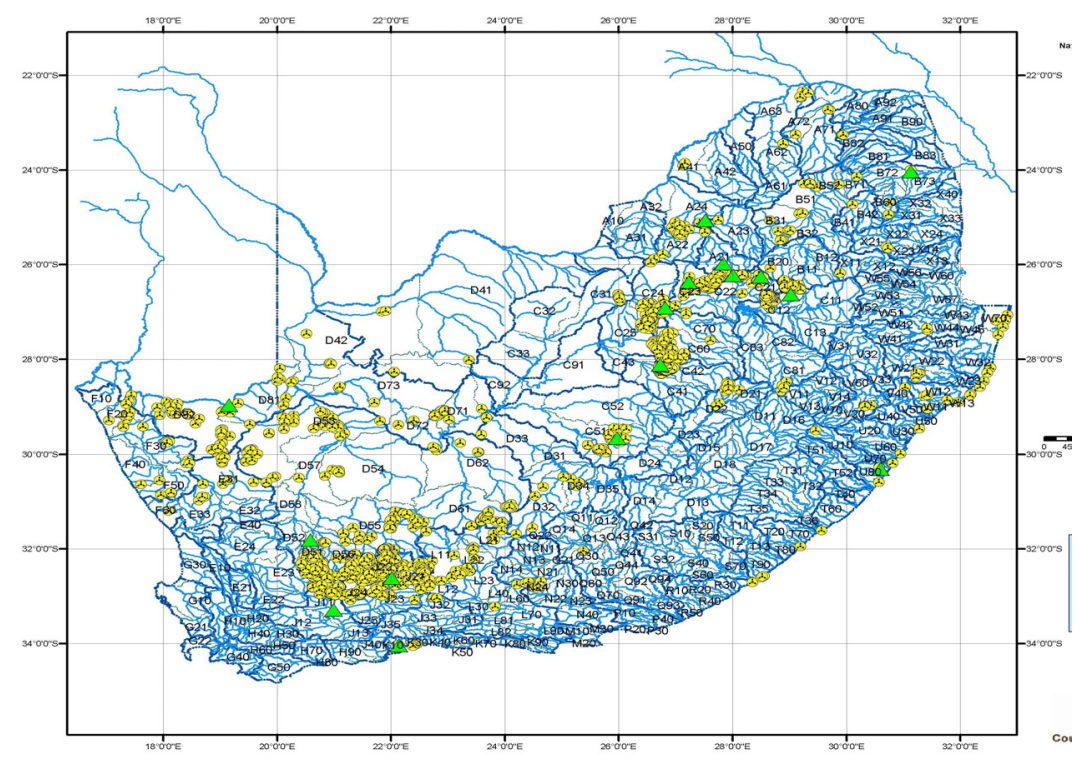

Figure 2: Selected sampling sites in tertiary catchments indicating radioactivity occurrences in South Africa.

\subsubsection{Variables of concern}

In order to be cost effective a screening method will be used to estimate the total radioactivity in the water resources. An element specific approach will only be followed where elevated levels of radioactivity have been identified.

The primary variables for screening purposes are:

- Gross alpha specific activity

- Gross beta specific activity

- Uranium chemical concentration

- Total potassium concentration 
- Gamma activity (Where elevated levels of man made radioactivity are expected).

- $\quad$ Total Dissolved Salts (TDS) and Electric Conductivity (EC).

The above variables are considered to be the most appropriate for estimating total radioactivity in the water resources and will be used for the NRMP to identify areas of concern. The most important variables to give an estimation of the radiological quality of the water resource are gross alpha and beta activity. The need for a specific radionuclide-analysis will depend on the screening results. The type of radionuclides that need to be analysed will also depend on the specific information from each monitoring point.

\subsubsection{Monitoring frequency}

Most surface water resources in South Africa exhibit a strong seasonal variation in water quality. Concentrations are generally lower during the rainfall period, and higher during the dry period [6]. These seasonal fluctuations are less pronounced in the higher rainfall areas of South Africa, than in the drier areas.

It is therefore very important to determine the central tendency of the water quality, as this is a more valid parameter to determine fitness for use, than the individual observations. The median value is in most cases the best indicator of central tendency of water quality and therefore the most used. The number of samples collected over a certain period of time, affects two important characteristics of water quality information. The first is the confidence interval around the central tendency, and the second is the power of trend detection. The more samples that are collected and analysed, the more confident one can be about the reported results.

A biweekly monitoring frequency has been recommended for the NRMP. This was determined statistically. However, if no radioactivity problems are identified at a specific point, the monitoring frequency will be reduced to once a month. But should there be any problems identified, a biweekly monitoring frequency will remain in use.

\subsubsection{Sample collection and handling}

Sample collection is the first step towards providing water quality information. As such it is one of the most important facets of the network. Not only is the collection of samples in itself relatively expensive, but also if it is not done properly and conscientiously, the network will yield unreliable information and the costs in analysis and data storage will be wasted [5].

The Department of Water Affairs and Forestry in collaboration with the Water Research Commission and the Department of Health have previously published a document on sampling and this document, with a few additions, will be used for the NRMP [1]. To limit the sample handling to a minimum field samples will be adequately coded and documented. Sampling and storage equipment that will ensure that the physical integrity of the samples is maintained under prevailing conditions (e.g. leakage resistance during transport), will be used. Final field samples will be properly labelled by using labelling material that is water-resistant. Labelling will also be done in a unique way to 
avoid confusion on the origin of the sample. If samples cannot be delivered directly to the laboratory by the field team, a reliable courier service will be used. Proper arrangements will be made in time with the selected laboratory to avoid problems that may be encountered if the laboratory does not accept samples during all hours and each day of the year. Laboratory personnel may not be on stand by to assure timely handling especially when filtration and preservation are still required. The NRMP will cover sampling in a wide variety of environmental conditions and special precautions will be taken by the field teams to protect them against hazards like ticks, snakes, spiders, rodents and most of all crime. All personnel involved in sampling and sample preservation will be properly trained.

\subsubsection{Sample analysis}

The basic philosophy behind the monitoring protocol is based mainly on costeffective analysis to evaluate the radiological risk of naturally occurring radioactive material. Sample analysis is one of the most expensive exercises of a monitoring programme and the availability of personnel and infrastructure plays a vital role in the sample analysis. The general protocol for the NRMP allows a gross alpha-beta measurement for the initial screening followed by a detailed analysis where elevated levels of radioactivity have been identified. An uncertainty of $10 \%$ may be allowed for screening purposes. In radioactivity measurements, the observed number of counts governs measurements statistics. The number of counts measured also depends on the time period over which a sample is counted.

\subsection{Data management and storage}

For any chronic exposures to radiation, the most important parameter that needs to be known is the radiation dose. The dose is given in millisievert per annum (mSv/a). Once gross alpha and beta measurements are completed, the activity $(\mathrm{Bq} / \mathrm{L})$ will be converted into the amount of radiation dose $(\mathrm{mSv} / \mathrm{a})$ an individual would be exposed to when drinking water from the source over time.

Results obtained from all the analysis will be processed on the WaterRad software. The WaterRad software is a computer based system that contains a dose calculation function and assessment guidelines used by DWAF to process the radiological data. The software converts the radioactivity data from Activity $(\mathrm{Bq} / \mathrm{l})$ to radiation dose $(\mathrm{Sv} / \mathrm{a})$ and classifies the water quality according to the dose evaluation and calculation guidelines [2]. Once the radioactivity data have been processed, it will be stored permanently on the Water Management System (WMS) database. The WMS is a database used by DWAF to store all water quality information from the various monitoring programmes.

\subsection{Information generation and dissemination}

Water quality information can be presented in different ways depending on the information requirements for a particular programme. The fundamental point of national water resource quality monitoring framework in South Africa is that all 
water resource quality monitoring should be information user centric [4]. The monitoring should be justified by serving the specified information users (primary and secondary) with information they needs required to perform their water resource management functions.

The information requirements of the NRMP are on a national level and they fit into the first tier of the national strategic framework for water quality monitoring [4]. Apart from the NRMP, regional and local monitoring programs may develop with their own monitoring programmes based on their own information requirements and information products. Primary users have a direct voice in monitoring design decisions while the secondary users are regarded as having an indirect voice because they may use and benefit from the information generated. Examples of primary users are: Minister of Water affairs and Forestry, Director general of DWAF, The Executive: Manager: Policy and Regulation, Water Quality Managers, Department of Minerals and Energy (DME), Department of Health (DoH), National Nuclear Regulator (NNR) etc. Examples of secondary users are: The general public, schools, students, researchers and Non Governmental Organisations (NGOs).

Table 1: Water quality assessment classification system for water resources in South Africa [3].

\begin{tabular}{|c|c|c|c|}
\hline $\begin{array}{l}\text { Class } \\
\text { / Colour }\end{array}$ & $\begin{array}{c}\text { Radioactive } \\
\text { Dose range } \\
\text { mSv/a }\end{array}$ & $\begin{array}{l}\text { Health Effects and Typical } \\
\text { Exposure Scenarios }\end{array}$ & $\begin{array}{c}\text { Intervention } \\
\text { Decision } \\
\text { Time Frames }\end{array}$ \\
\hline $\begin{array}{c}\text { Class 0 } \\
\text { (Blue - Ideal } \\
\text { water quality) }\end{array}$ & $0.01-0.10$ & $\begin{array}{l}\text { There are no observable health } \\
\text { effects. }\end{array}$ & $\begin{array}{l}\text { Intervention not } \\
\text { applicable for this } \\
\text { class of water. }\end{array}$ \\
\hline $\begin{array}{l}\text { Class } 1 \\
\text { (Green - Good } \\
\text { water quality) }\end{array}$ & $>0.10-1$ & No observable health effects. & $\begin{array}{l}\text { No intervention is } \\
\text { required although } \\
\text { ALARA principles } \\
\text { apply. }\end{array}$ \\
\hline $\begin{array}{c}\text { Class 2 } \\
\text { (Yellow } \\
\text { Marginal } \\
\text { water quality) }\end{array}$ & $>1-10$ & $\begin{array}{l}\text { A small increase in fatal } \\
\text { cancer risk associated with } \\
\text { this dose range. }\end{array}$ & $\begin{array}{l}\text { Intervention } \\
\text { considerations } \\
\text { within } 2 \text { years. }\end{array}$ \\
\hline $\begin{array}{c}\text { Class } 3 \\
\text { (Red - Poor } \\
\text { water quality) }\end{array}$ & $>10-100$ & $\begin{array}{l}\text { Health effects are statistically } \\
\text { detectable in very large } \\
\text { population groups. } \\
\text { This range represents } \\
\text { excessive exposure. }\end{array}$ & $\begin{array}{l}\text { Intervention is } \\
\text { required in less } \\
\text { than } 1 \text { year. }\end{array}$ \\
\hline $\begin{array}{c}\text { Class } 4 \\
\text { (Purple - } \\
\text { Unacceptable } \\
\text { water quality) }\end{array}$ & $>100$ & $\begin{array}{l}\text { Health effects may be } \\
\text { clinically detectable and a } \\
\text { significant increase in the fatal } \\
\text { cancer risk (greater than one } \\
\text { in a thousand). }\end{array}$ & $\begin{array}{l}\text { Immediate } \\
\text { intervention } \\
\text { required. }\end{array}$ \\
\hline
\end{tabular}

ALARA: As Low As Reasonably Achievable. 
Succinct reporting of information is very important and it must be ensured that the information provided to users is accurate, concise and appropriate to those that might need to use it. The reporting formats and the frequency of reporting must be strongly related to the information expectations of the monitoring system.

The radiological quality of the water resource will be presented in terms of fitness for use if the water from the source is consumed on a lifetime basis. The radiological quality will be described by a simplified colour classification system where each class indicates a dose range and the affected age group. (Table 1). The water quality classes represent annual dose for daily use (domestic purposes) associated health effects and the typical exposure scenario for a specific water source. [2]. Water quality maps will be used to present information on the status of the country's water resource whereas seasonal Kendal plots and Box and Whisker plots will be used to report information on trends.

\section{Conclusion}

The design of the National Radioactivity monitoring programme is in line with the requirements of the National water Act (Act 36 of 1998) and the Strategic Framework for National Water Quality Monitoring Programmes [3]. The NRMP contains the basic elements required for designing a water quality-monitoring programme. The manner in which sampling sites were selected, a biweekly monitoring frequency and the use of a screening method are regarded as the most cost-effective way of collecting information on the radiological status and trends of the water resources in South Africa. The sampling sites that were selected are giving good coverage of the country's surface water resources and it also allows for the identification of hotspots. As with other monitoring programmes, it is expected that the next phase, i.e. pilot implementation, will be faced with major challenges such as; lack of resources and of trained personnel. By training personnel during the pilot implementation phase of the programme, some of the capacity problems may be overcome by the time the programme is fully implemented. In order to save costs the number of sampling sites and the frequency of monitoring may have to be reduced. The implications of doing so will be assessed during the pilot implementation phase.

\section{Acknowledgement}

This paper is published with permission of Department: Water Affairs and Forestry.

\section{References}

[1] Department of Water Affairs and Forestry, Department of Health, and Water Research Commission (2000). Quality of domestic water suppliers Volume 2: Sampling Guide. First Edition. Water Research Commission Report No. TT 117/99. Pretoria. 
[2] Department of Water Affairs and Forestry (2002). Radioactivity dose calculation and water quality evaluation guideline for domestic water use. Report No. N/000/00/RDQ/0504, Resource Quality Services, Department of Water Affairs and Forestry, Pretoria, South Africa.

[3] Department of Water Affairs and Forestry, (2003). National Radioactivity Monitoring Programme: Phase 1 Needs Assessment. Report No. N/0000/REQ0703. Department of Water Affairs and Forestry, Resource Quality Services, Pretoria, South Africa

[4] DWAF (2004),. Strategic framework for national water resource quality monitoring programmes by DC Grobler and $\mathrm{M}$ Ntsaba. Report No. N/000/REQ0204. ISBN 0-621-35069-9. Resource Quality Services, Department of Water Affairs and Forestry, Pretoria, South Africa.

[5] Harris. J., Van Veelen. M., Gilfillan. T. C., (1992) Conceptual design report for a national river water quality assessment programme. WRC Report No 204/1/92.

[6] Bartram. J., Balance. R., (1992), Water Quality Monitoring: A practical guide to the design and implementation of freshwater quality studies and monitoring programmes

[7] Van Veelen M., Nell. U., and Geldenhuys. W, F., (1990) Surface water quality of South Africa, volume 2: drainage A and B. Technical report No. TR 145 Department of Water Affairs, Hydrological Research Institute 